\title{
Stretching of the Super-Elastic Double-Helix Geon. Wheeler's Thermal Geons as Quanta of Heat and Momentum. Bohm's Diffusion and the Heating of the Solar Corona and Heating of the Earth - Geon Engineering. Milgrom-Verlinde Constant. Mareš - Šesták constant. $(15.02 .2020)$
}

\author{
Jiří Stávek ${ }^{1}$ \\ ${ }^{1}$ Bazovského, Prague, Czech Republic \\ Correspondence: Jiří Stávek, Bazovského 1228, 16300 Prague, Czech Republic. E-mail: stavek.jiri@seznam.cz \\ Received: February 15, 2019 \\ Accepted: March 102019 \\ Online Published: March 25, 2020 \\ doi:10.5539/apr.v12n2p12 \\ URL: http://dx.doi.org/10.5539/apr.v12n2p12
}

\begin{abstract}
In our approach we have combined knowledge of Old Masters (working in this field before the year 1905), New Masters (working in this field after the year 1905) and Dissidents under the guidance of Louis de Broglie and David Bohm. Based on the great works of Julian Schwinger and John Archibald Wheeler we will study properties of geons formed by fusion of two soft x-ray particles (dyons) in the Schwarzschild gravitation core in our Sun at temperature $16 * 10^{6} \mathrm{~K}$. There are now several Teams that are able to achieve this fusion temperature in their special instruments (Tokamak, HL-2M Tokamak, Wendelstein 7-X, NIF, etc.) and to study properties of those formed geons. Thermal geons are with us all the time but they are very deeply hidden in our experiments. We have newly introduced Mareš - Šesták constant as the ratio of geon momentum to heat quantum of geon. The key information to enter into the World of geons was the empirical formula of David Bohm - the very well-known Bohm diffusion. From this formula we have extracted the amplitude, wavelength, frequency, quantum of the geon action, displacement law for geons, etc. It was found that geons are highly sensitive to the magnetic field strength. At a low magnetic field strength, the "inflation of geons" can occur. This effect could explain the Superheating of the Solar corona and the observed Heating of the Earth during two last centuries influenced by the changes in the Earth's magnetic field. Geon engineering might modify the geon volume through the magnetic field strength. On the other hand, we were stimulated by the works of Mordehai Milgrom and Eric Verlinde and derived the MilgromVerlinde constant describing the gravitational field strength leading to the Newtonian gravitational constant on thermodynamic principles. The quantum of the geon momentum might open a new way how to understand gravitational phenomena. Can it be that Nature cleverly inserted geons into our experimental apparatuses and into our very-well known Old Formulae? We want to pass this concept into the hands of Readers of this Journal better educated in the Mathematics, Physics, and Thermodynamics.
\end{abstract}

Keywords: Super-Elastic Double-Helix Geon, Stretching Effect in the Magnetic Field, Temperature Effect Mareš - Šesták Constant, "Geon Inflation", Geon Properties Hidden in Old Formulae, Bohm Diffusion, Advanced Tokamak and Nif Apparatus, Big G and Advanced NIF, Quantum of Heat, Quantum of Momentum, MilgromVerlinde Constant, Superheating of the Solar Corona, Heating of the Earth, Geon Engineering, "Nature Loves to Hide"

\section{Introduction}

The model of the double helix for the description of the photon wave appeared many times in the so-called dissident literature (outside of the mainstream literature). There are known many proposals for this double helix composition. Louis de Broglie proposed at the 1927 Solvay Conference his model of the full wave and the pilot guiding wave but could not give a deeper physical interpretation of his concept. Later Louis de Broglie (1939) proposed two component model of the photon. (Many modern Dissidents continue to develop this double-helix model of the photon where both helical paths are occupied by particles). In 1952 David Bohm rediscovered this pilot wave model and developed it as the de Broglie - Bohm theory. Since that time the concept of empty guiding waves remains still open and has been waiting for the physical interpretation. See J.S. Bell in 1992, L. Hardy in 1992, P.J. 
Lewis in 2007, W. Seager in 2018, and many others.

Can we use this model of the super-elastic double-helix for geons formed from two soft $\mathrm{x}$ - ray photons as it was predicted by Julian Schwinger and John Archibald Wheeler? Can we describe properties of this double-helix geon formed in the Schwarzschild gravitational core at $16 * 10^{6} \mathrm{~K}$ ? Solar geons are with us all the time but perfectly hidden and masked in our very well-known Old Formulae.

In order to achieve our target, we have to combine knowledge of Old Masters (working in this field before the year 1905), New Masters (working in this field after the year 1905), and Dissidents working on the double helix model of the photon for many years. The key breakthrough was found in the empirical formulae of David Bohm - Bohm diffusion. This Formula might guide us into the hidden World of Geons.

(We were inspired by the famous quote of Richard Feynman: "I learned a lot of things in biology, and I gained a lot of experience". We could find in those Laboratories stimulating experimental data about entropic force, enthalpic force and overstretching of the DNA double-helix.)

\section{Inspirations from Old Masters and New Masters - What is Heat? What is Temperature? What is Gravity?}

We were inspired by many Great Researchers working in this field for generations. In Table 1 and 2 we summarized some of those steps in our understanding of those topics. Words written in big capitals were critical for the model presented in the contribution.

Table 1. What is Heat? What is Temperature?

\begin{tabular}{l} 
What is Heat? What is Temperature? \\
\hline Heraclitus, Lucretius: MATERIAL SUBSTANCE “HEAT”, MATERIAL SUBSTANCE “COLD” \\
Comenius: CALORIC, FRIGERIC \\
Bacon, Descartes, Locke, Hooke, Huygens, Newton, Lomonosov: VIBRATION of some sort \\
Becher, Stahl: phlogiston \\
Black, Lavoisier, Laplace, Poisson, Fourier: CALORIC \\
Carnot: HEAT ENGINE EFFICIENCY \\
Count Rumford, Davy, Pictet: HEAT PRODUCTION BY FRICTION \\
Young, Herschel, Leslie, Melloni, Ampère, Maxwell: WAVE THEORY OF HEAT \\
Joule: MECHANICAL EQUIVALENT OF HEAT \\
Rankine, Clausius, Thomson, Helmholtz, Clapeyron: THERMODYNAMICS \\
Stefan, Boltzmann, Wien: thermodynamics with Maxwell's ENERGY-MOMENTUM RELATIONS \\
Planck: QUANTUM OF THE LEAST ACTION \\
Einstein: SPECIFIC HEATS \\
Bohm: EMPIRICAL BOHM DIFFUSION \\
Many Great New Masters continue to work on these topics \\
Wheeler: THERMAL GEONS \\
J.J. Mareš: WHAT IS HEAT? WHAT IS TEMPERATURE? \\
J. Šesták: WHAT IS TEMPERATURE?
\end{tabular}

Table 2. What is Gravity?

\begin{tabular}{l}
\hline \multicolumn{1}{c}{ What is Gravity? } \\
\hline Newton in 1687: "Hypotheses non fingo" GRAVITATIONAL FIELD STRENGTH \\
Newton in 1717: thinning of the aether density, PRESSURE DROP \\
Descartes, Huygens: vortex \\
Hooke: ALL BODIES EMTTING WAVES IN ALL DIRECTIONS \\
Le Sage: mechanical explanation \\
Euler: GRAVITATIONAL AETHER LOSES DENSITY in accordance with the inverse square \\
Lomonosov: AN ENORMOUS PENETRABILITY OF AETHER TROUGH BODIES \\
Herapath: THE AETHER IS HEATED BY BODIES and loses density, MOMENTUM of aether particles \\
Einstein: curved space-time \\
Many Great New Masters have been working on the QUANTUM GRAVITY \\
Milgrom: MOND, EMPIRICAL CONSTANT a \\
Verlinde: ENTROPIC FORCE
\end{tabular}


The key breakthroughs were found in the works of David Bohm - Bohm diffusion, Mordehai Milgrom - MOND and his empirical constant, and Eric Verlinde - his concept of the entropic force.

\section{Formation of Thermal Geons in the Schwarzschild Gravitational Core of the Sun}

Thermal geons formation in the Schwarzschild gravitational core of the Sun can be described as the Solar geon luminosity $\mathrm{L}_{\mathrm{G}}$ in watts:

$$
L_{G}=H_{0} M_{S} c^{2}=\sigma T_{S}^{4} 4 \pi R_{S}^{2} \approx 4.166 * 10^{29} \mathrm{~W}
$$

where $\mathrm{H}_{0}=2.33138^{*} 10-18 \mathrm{~kg} \mathrm{~kg}^{-1} \mathrm{~s}^{-1}$ is the constant describing formation of geons in the Sun core (known in astrophysics as $\mathrm{H}_{0}=71.9388 \mathrm{~km} \mathrm{~s}^{-1} \mathrm{Mpc}^{-1}$, today's experimental value is $\left.72.5 \pm 1 \mathrm{~km} \mathrm{~s}^{-1} \mathrm{Mpc}^{-1}\right), \mathrm{M}_{\mathrm{S}}$ is the mass of the Sun, $c$ is the light speed, $\sigma$ is the Stefan-Boltzmann constant, $T_{S}=16.09 * 10^{6} \mathrm{~K}$ is temperature inside of the Schwarzschild core, $\mathrm{R}_{\mathrm{S}}=2 \mathrm{GM}_{\mathrm{S}} / \mathrm{c}^{2}$ - the Schwarzschild gravitational radius of the Sun core.

Photons (super-elastic double-helix dyons) created in the Sun have been emitting to the outside of the Sun and also to the Schwarzschild gravitational core as the material for the thermal geon formation (super-elastic double-helix geon):

$$
2 \text { soft } X-\text { ray Dyons } \rightarrow \text { Geon }
$$

We know that the Solar photon luminosity is $\mathrm{L}_{\mathrm{S}}=3.827 * 10^{26} \mathrm{~W}$ and the Total Solar Irradiance at the Earth's orbit is TSI $\sim 1366 \mathrm{~W} / \mathrm{m}^{2}$. Therefore, we should experimentally observe the geon irradiance very easily. But the geon super-elastic double-helix adjust its heat content to the surroundings as:

$$
T S G I=\frac{L_{G}}{4 \pi R_{S-E}^{2}} \frac{k_{B}}{2 m_{g} c^{2}} T_{o r b i t} \approx 36 W \mathrm{~m}^{-2}
$$

where TSGI is the total solar geon irradiance at the Earth orbit and orbit temperature $\mathrm{T}_{\text {orbit }}=393,15 \mathrm{~K}$ and $\mathrm{m}_{\mathrm{g}}$ is the geon mass $\mathrm{m}_{\mathrm{g}}=1.2359^{*} 10^{-33} \mathrm{~kg}, \mathrm{R}_{\mathrm{S}-\mathrm{E}}$ is the distance from Earth's orbit to the Solar corona where geons were superheated once again to the corona temperature $\mathrm{T}_{\mathrm{C}}$ :

$$
T_{C}=T_{\text {orbit }} \sqrt{\frac{R_{S-E}}{R_{S}}} \approx 2.78 * 10^{6} \mathrm{~K}
$$

The same geon can reversibly adjust its heat content until the maximum temperature $T_{\mathrm{S}}=16,09 * 10^{6} \mathrm{~K}$. The constant $Z_{\mathrm{G}}$ describes the reversible adjustment of the geon heat content towards its surroundings temperature:

$$
Z_{G}=\frac{k_{B}}{2 m_{g} c^{2}}=6.21482 * 10^{-8} \mathrm{deg}^{-1}
$$

This is a very unique property of geons and might create the Geon Engineering Outshine Network (GEON) if we will be able to manipulate with these geons under the controlled conditions.

Geons formed in the Schwarzschild gravitational core create a super-elastic double-helix and the geon is running on the helical path with the Weber speed $\mathrm{c}_{\mathrm{W}}=\sqrt{2} \mathrm{c}$. Therefore, its energy content for the helical path is:

$$
m_{g} 2 c^{2}=k_{B} T_{S}
$$

For the longitudinal path along the double-helix we should write:

$$
E=m_{g} c^{2}=\frac{k_{B} T_{S}}{2}
$$

During its path outside of the Schwarzschild core the geon adjusts its heat content to the surroundings as: 


$$
E=m_{g} c V_{S t}=\frac{k_{B} T}{2}
$$

where $\mathrm{V}_{\mathrm{St}}$ is the stretching speed of that geon - a characteristic transverse vibration speed for the given surroundings temperature $\mathrm{T}$ :

$$
Y_{G}=\frac{V_{S t}}{T}=\frac{k_{B}}{2 m_{g} c} \approx 18.631561 \mathrm{~ms}^{-1} \mathrm{deg}^{-1}
$$

It could be very useful to discover more properties of these mysterious geons.

\section{What is the Temperature? Mareš - Šesták Constant}

Temperature, the central concept of thermal physics, is one of the most frequently employed physical quantities in common practice. There are many definitions of temperature as e.g.: "temperature is the manifestation of thermal energy, present in all matter (atoms, molecules, etc.), which is the source on the occurrence of heat, a flow of energy, when a body is in contact with another that is colder". All of these definitions are based on atomic or molecular kinetic energy of those particles. Jiří J. Mareš (2015) and Jaroslav Šesták (2019) have been trying to develop more rigorous treatment of temperature for many years. That is why we would like to introduce a new constant: Mareš - Šesták constant as ratio of the geon momentum to the heat quantum of geon as:

$$
T=X_{G} V_{S t}=\frac{\text { momentum of geon }}{\text { heat quantum of geon }} V_{S t}=\frac{2 m_{g} c}{k_{B}} V_{S t}=0.053672 \ldots\left[m^{-1} s \mathrm{deg}\right] V_{S t}\left[\mathrm{~ms}^{-1}\right]
$$

For the first time we have defined the temperature based on the geon properties - the ratio of geon momentum and the heat quantum of geon: Mareš - Šesták constant. The stretching speed $\mathrm{V}_{\mathrm{St}}$ describes the transverse vibration of geons that modify the kinetic energy of atoms and molecules. The maximum stretching speed equals $\mathrm{V}_{\mathrm{St}}=\mathrm{c}$ to the light speed. This the maximal temperature inside of the Schwarzschild gravitational core in the Sun.

\section{Bohm Diffusion, Beta of Plasma and Geon Properties}

David Bohm in 1949 conjectured the Bohm diffusion scaling for the diffusion of plasma across a magnetic field with the magnetic field strength $B$ :

$$
D_{B}=\frac{k_{B} T}{16 B e}
$$

The meaning of this empirical Bohm diffusion is actively discussed in the literature. The number 16 is only empirical constant and might be changed by a future modification.

We will extract from this equation amplitude $\mathrm{A}$, wavelength $\lambda$ and volume of geons $\mathrm{V}_{\mathrm{G}}$ as:

$$
\begin{gathered}
A=\frac{\lambda}{2 \pi}=\frac{1}{2 \pi} \frac{k_{B} T}{2} \frac{1}{B e c} \\
\lambda=\frac{k_{B} T}{2} \frac{1}{B e c} \\
V_{G}=\lambda \frac{k_{B}^{2} T^{2}}{16 \pi B^{2} e^{2} c^{2}}=\frac{2 \mu_{0}}{B^{2}} \frac{k_{B} T}{2}
\end{gathered}
$$

Because the geon is in the equilibrium with the magnetic field strength B in the surroundings, we can express Beta of plasma as: 


$$
\beta=1=\frac{\text { pressure of geon }}{\text { magnetic pressure }}=\frac{\frac{\text { energy of geon }}{\text { volume of geon }}}{\text { magnetic pressure }}=\frac{\frac{k_{B} T}{2} \frac{1}{V_{G}}}{\frac{B^{2}}{2 \mu_{0}}}
$$

After some re-arrangement we will get an expression for the geon wavelength $\lambda$ as:

$$
\lambda=8 \pi \mu_{0} e^{2} c \frac{2 c}{k_{B} T}=\frac{2 h_{G} c}{k_{B} T}=\frac{0.0105550 \ldots[m K]}{T}
$$

This is the displacement law for geons - an analogy with the Wien's displacement law for photons. The quantum of geon action can be evaluated as:

$$
h_{G}=8 \pi \mu_{0} e^{2} c=2.43048 \ldots{ }^{*} 10^{-34} J s
$$

We assume that geon brings heat energy to molecules as:

$$
E=\frac{5}{2} \frac{k_{B} T}{2}=\frac{5}{2} \frac{h_{G} c}{\lambda}=\frac{5}{2} h_{G} \nu
$$

(We were inspired by the expression for the specific heat at constant pressure $\mathrm{Cp}=5 / 2 * \mathrm{R}$ for ideal gases, where $\mathrm{R}$ is the gas constant). For the laboratory temperature $\mathrm{T}=300 \mathrm{~K}$ we will obtain effective geon wavelength $\lambda$ around $14 \mu \mathrm{m}$. We know that objects at room temperature will emit radiation concentrated mostly in the $8-25 \mu \mathrm{m}$ band. Is it just coincidence or geons are always present in our Rooms?

\section{Ideal Geon Law and Quantum of Heat - A Look into the Microworld}

We will try to formulate an analogy with the ideal gas law inspired by laws valid for macroworld - Boyle-Mariotte law, Charles law, Avogadro law, Gay-Lussac law, and the ideal gas law formulated by Clapeyron. For the values of the geon volume $\mathrm{V}_{\mathrm{G}}$, geon pressure $\mathrm{P}_{\mathrm{G}}$ and temperature $\mathrm{T}_{\mathrm{G}}$ we will get the quantum of heat $\mathrm{Q}_{\mathrm{G}}$ represented by one geon:

$$
\begin{gathered}
V_{G}=\frac{2 \mu_{0}}{B^{2}} \frac{k_{B} T_{G}}{2} \\
P_{G}=\frac{k_{B} T_{G}}{2 V_{G}} \\
Q_{G}=\frac{P_{G} V_{G}}{T_{G}}=\frac{k_{B}}{2}=\frac{m_{g} c V_{S t}}{T}=6.90325^{*} 10^{-24} \mathrm{~J} \mathrm{deg}^{-1}
\end{gathered}
$$

\section{Superheating in the Solar Corona and Heating of the Earth}

We can formulate Charles' Law (derived for the ideal gas by Jacques Charles) for geons as:

$$
\frac{V_{G}}{T_{G}}=\frac{2 \mu_{0}}{B^{2}} \frac{k_{B}}{2}
$$


The influence of the magnetic field strength B could be the explanation for the observed Superheating of the Solar Corona - the expansion of the geon volume in a very short time could dramatically increase temperature in that Solar Corona and create the observed Heliosheat ("inflation" of geon). E.g., the very important papers from L.F. Burlaga et al. (2009) and from T. Wiegelmann et al. (2014).

We expect a similar effect on the Earth' heating on a smaller scale, too. The influence of magnetic field around and inside of the Earth might dramatically influence the heat properties of geons. We want to pass this model to specialists on the Earth's magnetic field and to correlate the properties of the Earth's magnetic field with the growing temperature in the last two Centuries. This could be an important effect on the heating of the Earth and might play many orders more significant role in compare with other "heat molecules".

\section{Carnot's Heat Engine Efficiency}

We can re-formulate Sadi Carnot's heat engine efficiency $\eta$ as:

$$
\eta=\frac{\frac{k_{B} T^{H O T}}{2 m_{g} c}-\frac{k_{B} T^{C O L D}}{2 m_{g} c}}{\frac{k_{B} T^{H O T}}{2 m_{g} c}}=\frac{V_{S t}^{H O T}-V_{S t}^{C O L D}}{V_{S t}^{H O T}}
$$

In the Carnot heat engine geons change their transverse vibration speed expressed as the stretching speed $\mathrm{V}_{\mathrm{St}}$ and the released heat energy can be transformed into the work.

\section{Mechanical Equivalent of Heat (MEH)}

The MEH states that motion and heat are mutually interchangeable and that in every case, a given amount of work would generate the same amount of heat, provided the work done is totally converted to heat energy.

Today a standardized value of MEH $=4.1860 \mathrm{~J} \mathrm{cal}^{-1}$.

This value is based on the experiments with water and its specific heat $\mathrm{Cp}$ at constant pressure:

$\mathrm{Cp}=4185.5 \mathrm{Jkg}^{-1} \mathrm{~K}^{-1}$ at $15^{\circ} \mathrm{C}, 101.325 \mathrm{kPa}$.

(It is known that specific heat $\mathrm{Cp}$ of water varies between $4.17-4.22 \mathrm{~J} / \mathrm{g} /{ }^{\circ} \mathrm{C}$.)

We propose to express MEH as the ratio of a geometrical factor $4 \pi$ describing the space distribution of geons from its source and number 3 describing the number of degrees of freedom of geons:

$$
M E H=\frac{4 \pi}{3}=\frac{\text { space distribution of geons }}{3 \text { deg rees of freedom }}=4.1887902 \ldots \mathrm{J} \mathrm{cal}^{-1}
$$

\section{Fine Structure of Dyons and Geons}

There are known many interpretations of the dimensionless number $\alpha$ - the famous fine structure describing something in the microworld. There are more than ten different interpretations and many numerical attempts to derive the value of the fine structure constant.

We propose to interpret the fine structure as the ratio of two forces $-\mathrm{F}_{\mathrm{C}}-$ the Coulomb force and $\mathrm{F}_{\mathrm{N}}$ - the Newton force - both in the co-operation govern the motion of dyon (photon) on the super-elastic double-helix with one occupied helix and one empty helix (the concept introduced by David Bohm):

$$
\alpha=\frac{F_{C}}{F_{N}}=\frac{\frac{1}{4 \pi \varepsilon_{0}} \frac{e^{2} 4 \pi^{2}}{\lambda^{2}}}{\frac{2 \pi m c^{2}}{\lambda}}=\frac{1}{4 \pi \varepsilon_{0}} \frac{2 \pi e^{2}}{h c}
$$

We can relate both quanta of actions for photons $\mathrm{h}$ and for geons $\mathrm{h}_{\mathrm{G}}$ through the fine structure $\alpha$ as:

$$
\alpha=\frac{\mu_{0}}{4 \pi} \frac{2 \pi e^{2} c}{h}=\frac{h_{G}}{16 \pi h}
$$


It seems that this interpretation of the fine structure constant might bring to us some more information from the Microworld of dyons and geons.

\section{Gravitation Field Strength - Milgrom- Verlinde Constant}

Gravitation field strength describes the influence of a source mass M producing force on the test mass $\mathrm{m}$. The gravitation field strength is measured in newtons per kilogram $(\mathrm{N} / \mathrm{kg})$.

For the source mass $M=1 \mathrm{~kg}$, test mass $\mathrm{m}=1 \mathrm{~kg}$ and the distance of their centers $\mathrm{R}=1 \mathrm{~m}$ we can derive MilgromVerlinde constant $C_{P}(N / \mathrm{kg})$ based on the thermodynamics rules and laws. We used the symbol $C_{P}$ because in thermodynamics the specific heat for ideal gas at constant pressure is given as: $C_{P}=5 / 2 \mathrm{R}$ where $\mathrm{R}$ is the gas constant. The factor " $5 / 2$ " plays a very important role in thermodynamics describing number of degrees of freedom for monoatomic ideal gas at the constant pressure.

For one geon we can write the quantum of geon momentum $\mathrm{c}$ as:

$$
c_{P}=m_{G} c \frac{3}{4 \pi}=8.84536 * 10^{-26} \mathrm{~kg} \mathrm{~m} \mathrm{~s}^{-1} \approx 165.5 \mathrm{eV} / \mathrm{c}
$$

For $\mathrm{N}$ number of geons reflected from the source $\mathrm{M}=1 \mathrm{~kg}$ towards the test mass $\mathrm{m}=1 \mathrm{~kg}$ at the distance between their centers $\mathrm{R}=1 \mathrm{~m}$ we can write:

$$
C_{P}=\frac{N}{k g s} m_{G} c \frac{3}{4 \pi}=\frac{N}{k g s} \frac{k_{B} T}{2 V_{S t}} \frac{3}{4 \pi}=\frac{5}{2} \frac{F}{m}=\frac{5}{2} \frac{G^{*} 1}{1^{2}}
$$

Now, we will insert the constant $\mathrm{H}_{0}$ where this constant has a different meaning $-\mathrm{H}_{0}=2.33138^{*} 10^{-18} \mathrm{~kg} \mathrm{~kg}^{-1} \mathrm{~s}^{-1}$ is the constant describing the mass of reflected geons from the source mass $\mathrm{M}=1 \mathrm{~kg}$ towards to the test mass $\mathrm{m}=1$ $\mathrm{kg}$ at the distance $\mathrm{R}=1 \mathrm{~m}$ (it is known in astrophysics as $\mathrm{H}_{0}=71.9388 \mathrm{~km} \mathrm{~s}^{-1} \mathrm{Mpc}^{-1}$, today's experimental value is $\left.72.5 \pm 1 \mathrm{~km} \mathrm{~s}^{-1} \mathrm{Mpc}^{-1}\right)$. We will get:

$$
C_{P}=H_{0} c \frac{3}{4 \pi}=\frac{H_{0}}{m_{g}} \frac{k_{B} T}{2 V_{S t}} \frac{3}{4 \pi}=\frac{5}{2} \frac{F}{m}=\frac{5}{2} \frac{G^{*} 1}{1^{2}}
$$

For the value $\mathrm{G}=6.6743 * 10^{-11} \mathrm{~m}^{3} \mathrm{~kg}^{-1} \mathrm{~s}^{-2}$ we will get:

$$
C_{P}=\frac{5}{2} \frac{F}{m}=\frac{5}{2} \frac{G^{*} 1}{1^{2}}=1.6685 \ldots * 10^{-10} \mathrm{~N} / \mathrm{kg}
$$

We want to name this constant as the Milgrom - Verlinde constant: it was known from the MOND literature that Mordehai Milgrom's empirical value $\mathrm{a}_{0} \approx(1.2 \pm 0.2) * 10^{-10} \mathrm{~m} \mathrm{~s}^{-2}$ might explain a lot of experimental data in astrophysics but there is still missing an interpretation for this empirical value. On the other site, Eric Verlinde with his great contributions on the entropic gravitational force opened a new path where we should search for an interpretation of this empirical value $\mathrm{a}_{0}$.

We want to pass this concept into the hands of experienced Readers of this Journal dealing with the Big G and the MOND interpretation.

\section{Entropic Force, Enthalpic, Force and Overstretching of the DNA Double-Helix}

We were inspired by the famous quote of Richard Feynman: "I learned a lot of things in biology, and I gained a lot of experience". We could find in those Laboratories stimulating experimental data about entropic force, enthalpic force and overstretching of the DNA double-helix.

There were published a lot of experimental data describing the DNA double-helix stretching. There were observed three regions with entropic force, enthalpic force and overstretching. E.g., Joost van Mameren (2009) the Figure 4, D. Murugesapillai et al. (2017) the Figure 2, and many other papers.

We propose to make similar experiments for geons. It could be a new explanation for the so-called "missing dark matter". 


\section{Conclusions}

1. We have combined knowledge of Old Masters, New Masters, and Dissidents in order to newly formulate events observed with heat and gravity.

2. We have postulated formation of geons in the Schwarzschild gravitation core in the Sun.

3. Geons can reversibly adjust their transverse vibration - the stretching speed - and thus dramatically change their heat content.

4. We have newly defined the Mareš - Šesták constant for the definition of temperature based on geons properties.

5. Inspired by the expression for the Bohm diffusion we have extracted values for amplitude, frequency, displacement law, and the quantum of the action for geons.

6. At room temperature we should observe heat effect of geons at $14 \mu \mathrm{m}$ - the effective wavelength of geons at that temperature.

7. We have derived the ideal geon law and the geon heat quantum.

8. Geon Superheating in the Solar corona was interpreted as the geon inflation at low magnetic field strength.

9. Carnot heat engine efficiency was interpreted as the change of the geon stretching speed.

10. Mechanical Equivalent of Heat was interpreted as the ratio of the geon space distribution and 3 degrees of freedom of geons.

11. Fine structure constant was newly interpreted for dyons (photons) and geons.

12. Quantum of momentum of geons was defined.

13. Gravitation field strength was defined as the Milgrom - Verlinde constant.

14. We need more experimental data for the entropic force, enthalpic force and overstretching of the super-elastic double-helix of geons.

15. Nature might hide Her Beauty in plain sight protected by the mathematical camouflage.

16. We want to pass this model into hands of Readers of this Journal better educated in Mathematics, Physics and Thermodynamics.

\section{Acknowledgments}

This work was supported by the JP\&FŠ Agency (Contract Number 25g/1963), by the VZ\&MŠ Agency (Contract Number 16000/1989), by the GMS Agency (Contract Number 69110/1992), and by the FH\&ES Agency (Contract Number 1502/2020). We were supported by the contract numbers 28101918/2018, 58287/2019. We have found the valuable support on the web site www.wolframalpha.com with the corrections of used formulae.

\section{Conflict of interests}

The authors declare that there is no conflict of interests regarding the publication of this paper.

\section{References}

Anderson, P. R., \& Brill, D. R. (1997). Gravitational Geons Revisited. Arxiv: gr-qc/9610074v2.

Aoki et al. (2018). Massive Graviton Geons. Arxiv: 1710.05606v2.

Apollonius of Perga. On the Cochlias. In L. Euclid (Ed.), Friedlein (Vol. 105, pp. 1-6).

Ashworth, R. A. (1998). Confirmation of Helical Travel of Light through Microwave Waveguide Analysis. Physics Essays, 11, 1-10. https://www.researchgate.net/publication/260829054_Confirmation_of_Helical_ Travel_of_Light_through_Microwave_Waveguide_Analyses

Bardini, G., \& Gianella, G. M. (2016). A Historical Walk along the Idea of Curvature, from Newton to Gauss Passing from Euler. International Mathematical Forum, 11, 259-278. http://www.m-hikari.com/imf/imf2016/5-8-2016/p/bardiniIMF5-8-2016.pdf

Bell, J. S. (1992). Six Possible Worlds of Quantum Mechanics. Foundations of Physics, 22, 1201-1215.

Blåsjö, V. (2017). Transcendental Curves in the Leibnizian Calculus. Academic Press, Elsevier, ISBN: 978-0-12813237-1.

Blåsjö, V. (2018). Mathematicians Versus Philosophers in Recent Work on Mathematical Beauty. Journal of Humanistic Mathematics, 8, 414-431. https://scholarship.claremont.edu/cgi/viewcontent.cgi?referer=https:/ $/$ www.google.com/\&httpsredir=1\&article=1380\& context $=$ jhm 
Boccaletti et al. (1970). Conversion of Photons into Gravitons and Vice Versa in a Static Electromagnetic Field. Il Nuovo Cimento, LXX, 129-146.

Bohm, D. (1949). In A. Guthrie \& R. K. Wakkreling (Eds.), The Characteristics of Electrical Discharges in Magnetic Fields. New York: McGraw-Hill.

Bohm, D. (1952). A Suggested Interpretation of the Quantum Theory in Terms of Hidden Variables, I. Physical Review, 85, 166-179.

Bohm, D. (1989). Quantum Theory. Dover Publications, ISBN-10: 9780486659695.

Böhm, J. (2016). Wonderful World of Pedal Curves. http://rfdz.phnoe.ac.at/fileadmin/Mathematik_Uploads/ACDCA/TIME2016/Boehm_Pedals_pdf

Brackenridge, J. B. (1996). The Key to Newton's Dynamics: The Kepler Problem and the Principia. Berkeley: University of California Press. ISBN: 978-0520202177.

Bruneau, O. (2015). ICT and History of Mathematics: The Case of the Pedal Curves from 17th Century to 19th Century. https://hal.archives-ouvertes.fr/hal-01179909/document

Bultinck et al. (2010). The Origin of Bohm Diffusion, investigated by a Comparison of Different Modelling Methods. J. Physics D-Applied Physics, 43, 29-34.

Burlaga, L. F., Ness, N. F., \& Acuña, M. H. (2009). Magnetic Field Strength Fluctuations and Temperature in the Heliosheath. Astrophysical Journal, 691, L82-86.

Cohen et al. (2019). Realism and Causality I: Pilot Wave and Retrocausal Models as Possible Facilitators. Arxiv: $1902.05108 \mathrm{v} 2$.

Cohen, I. B. (1999). A Guide to Newton's Principia. The Principia: The Mathematical Principles of Natural Philosophy. Berkeley, CA, University California Press. ISBN: 978-0-520-08816-0.

Cohen, I. B., \& Smith, G. E. (Eds.) (2004). The Cambridge Companion to NEWTON. Cambridge University Press, Cambridge, ISBN 0-521-65696-6.

Cook, T. A. (1914). The Curves of Life. Constable and Company, London.

Cylindrical Helix. http://demonstrations.wolfram.com/SineAndCosineHelix/

Cylindrical Helix. http://mathworld.wolfram.com/Helix.html

Cylindrical Helix. https://en.wikipedia.org/wiki/Helix

Cylindrical Helix. https://www.mathcurve.com/courbes3d.gb/helicecirculaire/helicecirculaire.shtml

Darrigol, O. (2012). A History of Optics. From Greek Antiquity to the Nineteenth Century. Oxford University Press. Oxford. ISBN-10: 0199644373.

De Broglie - Bohm Theory. https://en.wikipedia.org/wiki/De_Broglie\%E2\%80\%93Bohm_theory

De Broglie, L. (1927). Electrons et Photons: Rapport et Discussions du Cinquième Conseil de Physique tenu à Bruxelles du 24 au 29 Octobre 1927. Gauthier-Villars.

De Broglie, L. (1939). Matter and light: The New Physics (pp. 136-142). W.W: Norton CO., New York.

Deffner, S., \& Campbell, S. (2019). Quantum Thermodynamics: An Introduction to the Thermodynamics of Quantum Information. Morgan \& Claypool Publishers, ISBN: 978-1-64327-658-8.

Dennis, D. (1995). Historical Perspectives for the Reform of Mathematics Curriculum: Geometric Curve Drawing Devices and their Role in the Transition to an Algebraic Description of Functions. Dissertation at Cornell University. http://www.quadrivium.info/mathhistory/CurveDrawingDevices.pdf

Dürer, A. (1525). Underweysung der Messung, mit dem Zirckel und Richtscheyt, in Linien, Ebenen und gantzen corporen. (Dürer's Plan for the Cylindrical Helix in a Staircase) in https://commons.wikimedia.org/wiki/Category:Underweysung_der_Messung

Dürr, D., \& Teufel, S. (2009). Bohmian Mechanics: The Physics and Mathematics of Quantum Theory Fundamental Theories of Physics. Springer, ISBN 10-3540893431.

Earth's Magnetic Field. https://en.wikipedia.org/wiki/Earth\%27s_magnetic_field

Einstein, A. (1905). On a Heuristic Point of View Concerning the Production and Transformation of Light. Annalen der Physik, 17, 132-148. 
Entropic Gravity. https://en.wikipedia.org/wiki/Entropic_gravity

Experimental Advanced Superconducting Tokamak. https://en.wikipedia.org/wiki/Experimental_Advanced_ Superconducting_Tokamak

Feynman, R. (1964). Quantum Behavior. Feynman Lectures, III(1). http://www.feynmanlectures.caltech.edu/III_01.html

Fine Structure Constant. https://en.wikipedia.org/wiki/Fine-structure_constant

Ford, K., \& Wheeler, J. A. (2000). Geons, Black Holes, and Quantum Foam: A Life in Physics. W.W: Norton \& Company, ISBN-10: 0393319911.

Freire, O. (2003). Science and Exile: David Bohm, the Hot Times of the Cold War, and his Struggle for a New Interpretation of Quantum Mechanics. https://arxiv.org/ftp/physics/papers/0508/0508184.pdf

Freire, O. (2015). The Quantum Dissidents: Rebuilding the Foundations of Quantum Mechanics (1950-1990). With a Forword by S.S. Schweber. Springer, ISBN-10: 9783662446614.

Fried, M., \& Unguru, S. (2001). Apollonius of Perga's Conica: Text, Context, Subtext. Mnemosyne, Bibliotheca Classic. ISBN-10: 9004119779.

Gant, de F. (1995). Force and Geometry in Newton's Principia. Princeton University Press, Princeton. ISBN 0691-03367-6.

Gauthier, R. (2017). Entangled Double-Helix Superluminal Composite Photon Model Defined by Fine Structure Constant. https://www.researchgate.net/publication/320840733_Entangled_Double-Helix_Superluminal_ Composite_Photon_Model_Defined_by_Fine_Structure_Constant

Geminus of Rhodes: Cylindrical Helix. https://www-history.mcs.st-and.ac.uk/Biographies/Geminus.html

Gerber, P. (1898). Die räumliche und zeitliche Ausbreitung der Gravitation. Zeitschrift für Mathematik und Physik, 43, 93-104. http://www.mahag.com/fremd/gerber.htm

Guicciardini, N. (2003). Reading the Principia: The Debate on Newton's Mathematical Methods for Natural Philosophy from 1687 to 1736. Cambridge University Press, Cambridge. ISBN-10: 0521544033.

Hadot, P. (2008). The Veil of Isis: An Essay on the History of the Idea of Nature. Belknap Press. ISBN-10: 0674030494.

Hall, A. R. (2015). Philosophers at War: The Quarrel Between Newton and Leibniz. Cambridge University Press. ISBN: 052152489X.

Hardy, L. (1992). On the Existence of Empty Waves in Quantum Theory. Physics Letters A, 167, 11-16.

Hawking, S. W., \& Israel, W. (1987). Three Hundred Years of Gravitation. Cambridge University Press, ISBN10:0521343127.

Heat, T. L. (2015). Apollonius of Perga: Treatise on Conic Sections. Carruthers Press. ISBN-10: 1446021262.

Heat. https://en.wikipedia.org/wiki/Heat

Helical Electromagnetic Waves. (2011). http://blackholeformulas.com/files/EnM.html

Heron. (1912). Heronis Alexandrini opera quae supersunt omnia. Teubner, Leipzig, Ed. And translated into German by J.L. Heiberg.

History of Thermodynamics. https://en.wikipedia.org/wiki/History_of_thermodynamics

Huygens, Chr. (1678). Traité de la Lumière, Leyden, Van der Aa. (In Treatise on Light, London: McMillan, 1912).

Ideal Gas Law. https://en.wikipedia.org/wiki/Ideal_gas_law

Interpretations of Quantum Mechanics. https://en.wikipedia.org/wiki/Interpretations_of_quantum_mechanics

Kawasaki, A. (2019). Measurement of the Newtonian Constant of Gravitation by Precision Displacement Sensors. Arxiv: $1903.11223 \mathrm{v} 1$.

Kleinevo $\beta$, U. (2002). Bestimmung der Newtonschen Gravitationskonstanten. G. PhD Thesis, University Wuppertal, WUB-DIS-2002-2.

Köller, J. (2016). Fusspunktkurven und Gegenfusspunktkurven. http://www.mathematische-basteleien.de/ fusspunktkurve.htm 
Kroupa, P., Pawlowski, M., \& Milgrom, M. (2012). The Failures of the Standard Model of Cosmology Require a New Paradigm. Int. J. of Modern Physics D, 21, 1230003.

Kvasz, L. (2012). Galileo, Descartes, and Newton - Founders of the Language of Physics. Acta Physica Slovaca, 62, 519-614. http://www.physics.sk/aps/pubs/2012/aps-12-06/aps-12-06.pdf

Laird, W. R., \& Roux, S. (Eds.) (2008). Mechanics and Natural Philosophy before the Scientific Revolution. Springer. ISBN 978-90-481-7491-1.

Levitt, L. S. (1978). Is the Photon a Double Helix? Lettere al Nuovo Cimento, 21, 222-223.

Lewis, P. J. (2007). Empty Waves in Bohmian Quantum Mechanics. British Journal for the Philosophy of Science, $58,787-803$.

List of Quantum Gravity Researchers. https://en.wikipedia.org/wiki/List_of_quantum_gravity_researchers

Lockwood, E. H. (1961). A Book of Curves. Cambridge University Press. http://www.aproged.pt/biblioteca/ ABookofCurvesLockwood.pdf

Mameren, J., Woyniak, A., \& Ragona, S. (2009). Single-Molecule DNA Stretching Using Optical Tweezers. Microsocopy Today, Janaury 2009, 42-43.

Mancosu, P., \& Arana, A. (2010). Descartes and the Cylindrical Helix. Historia Mathematica, 37, 403-427. https://www.sciencedirect.com/science/article/pii/S0315086009000949

Maor, E., \& Jost, E. (2014). Beautiful Geometry. Princeton University Press, Princeton. ISBN-13:978-0-69115099-4.

Mareš et al. (2008). Phenomenological Approach to the Caloric Theory of Heat. Thermochimica Acta, 474, 16-24.

Mareš, J. J. (2015). Do we know what the Temperature is? Journal of Thermal Analysis and Calometry, 120, $223-$ 230. https://arxiv.org/ftp/arxiv/papers/1604/1604.05563.pdf

McGaugh, S. (2015). A Tale of Two Paradigms: The Mutual Incommensurability of LCDM and MOND. Canadian Journal of Physics, 93, 250-259.

Milgrom, M. (2014). MOND Theory. Arxiv. 1404.7661v2.

Milgrom, M. (n. d.). A Modification of the Newtonian Dynamics as a Possible Alternative to the Hidden Mass Hypothesis. Astrphysical Journal, 270, 365-370.

Modified Newtonian Dynamics (MOND). https://en.wikipedia.org/wiki/Modified_Newtonian_dynamics

Murugesapillai et al. (2017). Single-molecule Studies of High-mobility Group B Architectural DNA Bending Proteins. Biophys. Rev., 9, 17-40, Figure 2. https://ink.springer.com/article/10.1007/s12551-016-0236-4

National Ignition Facility (NIF). https://en.wikipedia.org/wiki/National_Ignition_Facility

Nauenberg, M. (1993). Newton's Early Computational Method for Dynamics. https://core.ac.uk/download/pdf/82476251.pdf

Nauenberg, M. (2018). Newton's Graphical Method for Central Force Orbits. Am. J. Phys., 86, 765-771.

Nauenberg, M. (2018). Visiting Newton's Atelier before the Principia, 1679-1684. Arxiv: 1805.06871v.

Newton, I. (1687). The Principia. Mathematical Principles of Natural Philosophy. Translated by I.B. Cohen and A. Whitman. University California Press, Berkeley. ISBN 978-0-520-08816-0.

Newton, I. (1704). Optics: Or, a treatise of the reflections, refractions, inflexions, and colors of light. Also two treatises of the species and magnitude of curvilinear figures. Palo Alto, Calif:: Octavo, ISBN 1-891788-04-3.

Parks, H. V., \& Faller, J. E. (2010). A Simple Pendulum Determination of the Gravitational Constant. Arxiv: $1008.3203 \mathrm{v} 3$.

Pedal curves properties. (2018). https://en.wikipedia.org/wiki/Pedal_curve

Perry, G. P., \& Cooperstock, F. I. (1998). Stability of Gravitational and Electromagnetic Geons. Arxiv: gr$\mathrm{qc} / 9810045 \mathrm{v} 1$.

Pilot Wave Theory and Quantum Realism. (2016). Space Time, PBS Digital Studios. https://www.youtube.com/watch?v=R1XdsyctD50

Pilot Wave Theory. https://en.wikipedia.org/wiki/Pilot_wave_theory 
Pladevall, X. O., \& Mompart, J. (2019). Applied Bohmian Mechanics: From Nanoscale Systems to Cosmology. 2nd Ed., Jenny Stanford Publishing, ISBN 10-9814800104.

Planck, M. (1901). On the Law of Distribution of Energy in the Normal Spectrum. Annalen der Physik, 4, 553.

Power, E. A., \& Wheeler, J. A. (1957). Thermal Geons. Rev. Mod. Phys., 29, 480.

Quantum Gravity. https://en.wikipedia.org/wiki/Quantum_gravity

Rothleitner, C., \& Schlamminger, S. (2017). Invited Review Article: Measurements of the Newtonian Constant of Gravitation. G. Rev. Sci. Instrum., 88, 111101-1.

Roveli, C. (2018). Physics Needs Philosophy. Philosophy Needs Physics. Found. Phys., 48, 481-491. https://arxiv.org/ftp/arxiv/papers/1805/1805.10602.pdf

Sanduk, M. I. (1997). The Factor 1/16 of Bohm Diffusion. Indian Journal of Physics, 71B, 495-502.

Schumacher, A. (1999). Systematische Untersuchungen zur Messung der Newtonschen Gravitationskonstanten mit einem Pendelresonator. PhD Thesis, University of Wuppertal, WUB-DIS-99-13.

Schwarzschild, K. (1916). Über das Gravitationsfeld eines Massenpunktes nach der Einstein'schen Theorie. Sitzungsberichte der Königlich-Preussischen Akademie der Wissenschaften, Reimer, Berlin.

Schwinger, J. (1976). Gravitons and Photons: The Methodological Unification of Source Theory. General Relativity and Gravitation, 7, 251-256.

Seager, W. (2018). The Philosophical and Scientific Metaphysics of David Bohm. Entropy, 20, 493.

Šesták, J. (2005). Science of Heat and Thermophysical Studies. 10.1016/B978-0-444-51594-2.X5000-0.

Šesták, J. (2019). Do we really know what temperature is: From Newton' cooling law to an improved understanding of thermal analysis. J. Thermal Analysis and Calorimetry.

Smolin, L. (2017). Three Roads to Quantum Gravity. Basic Books, ISBN-10:0465094546.

Stávek, J. (2019). Super-Elastic Double-Helix Model of Photon. Huygens-de Broglie Particle on the Helical Path Guided by the Newton-Bohm Entangled Helical Evolute. Quantum of Magnetic Flux Based on the Mathematical Beauty of Newton, Lorentz, Einstein, Dirac, Gell-Mann, Schwinger, Polchinski and Witten (16.06.2019). Appl. Phys. Res., 11, 40-51.

Stávek, J. (2020). Squeezing of the Super-Elastic Double-Helix Photon in the Gravitational Field (Hidden in Very Well- Known Old Formulae). Pound-Rebka-Snider Effect Studied by the Advanced LIGO Instrument, Pioneer Anomaly and CMB (Cosmic Microwave Background). (23.11.2019). Applied Physics Research, 12, $8-18$.

Temperature. https://en.wikipedia.org/wiki/Temperature

Theo Murphy Meeting Issue. (2014). The Newtonian Constant of Gravitation, a Constant too difficult to measure? Philos. Trans A Math Phys. Eng. Sci., 372(2026).

Thorne, K. S. (1995). Black Holes \& Time Warps. W.W. Norton \& Company. ISBN-10:0393312763.

Thorne, K. S. (2019). John Archibald Wheeler. Arxiv: 1901/1901.06623.

Tokamak. https://en.wikipedia.org/wiki/Tokamak

Tombe, F. D. (2019). The 1855 Weber-Kohlrausch Experiment (The Speed of Light). The General Science Journal. https://www.scribd.com/document/294114501/The-1855-Weber-Kohlrausch-Experiment-The-Speed-ofLight

Verlinde, E. P. (2011). On the Origin of Gravity and the Laws of Newton. JHEP, 4, 29. Arxiv: 1001.0785.

Walleczek, J., Grossing, G., \& Pylkkanen, P. (2019). Emergent Quantum Mechanics: David Bohm Centennial Perspectives. Mdpi AG, ISBN-10:3038976165.

Watson, J. D. (2001). The Double Helix: A Personal Account of the Discovery of the Structure of DNA. Touchstone, ISBN-10: 9780743216302.

Wheeler, J. A. (1955). Geons. Physical Review, 97, 511.

Wheeler, J. A. (1957). On the Nature of Quantum Geometrodynamics. Annals of Physics, 604-614.

Wiegelmann, T., Thalmann, J., \& Solanki, S. K. (2014). The Magnetic Field in the Solar Atmosphere. Arxiv: $1410.4214 \mathrm{v} 1$. 
Wien's Displacement Law. https://en.wikipedia.org/wiki/Wien\%27s_displacement_law

Wilczek, F. (2016). Physics in 100 years. Physics Today, 69, 32-39.

Williams, G. (2019). Unravelling the Double Helix. The lost Heroes of DNA. Weidenfeld \& Nicholson, ISBN-10: $147460935 \mathrm{X}$.

Williams, M. C. (2002). Optical Tweezers: Measuring Piconewton Forces. In P. Schwille (Ed.), Single Molecules Techniques, Biophysics Textbook Online. https://pdfs.semanticscholar.org/8f03/9df534bb8243862917 aefa54acc532e09baa.pdf?_ga=2.14133687.1286308283.1581690448-447900398.1574672695

Wu et al. (2019). Progress in Precise Measurements of the Gravitational Constant. Annalen der Physik (Berlin), $531,1900013$.

Yates, R. C. (1974). Curves and their Properties. National Council of Teachers of Mathematics, ISBN: 10087353039X.

Zank et al. (2004). Perpendicular Diffusion Coefficient for Charged Particles of Arbitrary Energy. J. Geophysical Research, Space Physics, 109(A4).

\section{Copyrights}

Copyright for this article is retained by the author(s), with first publication rights granted to the journal.

This is an open-access article distributed under the terms and conditions of the Creative Commons Attribution license (http://creativecommons.org/licenses/by/4.0/). 